\title{
DTC based on SVM for induction motor sensorless drive with fuzzy sliding mode speed controller
}

\author{
Sarra Massoum ${ }^{1}$, Abdelkader Meroufel ${ }^{2}$, Ahmed Massoum ${ }^{3}$, Wira Patrice ${ }^{4}$ \\ ${ }^{1,2,3}$ Faculty of Electrical Engineering, Djillali Liabe University, Algeria \\ ${ }^{4}$ Université de Haute-Alsace, UHA (IRIMAS), France
}

\begin{tabular}{l} 
Article Info \\
\hline Article history: \\
Received Mar 15, 2020 \\
Revised Jul 8, 2020 \\
Accepted Jul 25, 2020 \\
\hline Keywords: \\
Direct torque control \\
Fuzzy sliding mode controller \\
Induction motor \\
Model reference adaptive \\
system \\
Sensorless
\end{tabular}

\footnotetext{
Corresponding Author:

Ahmed Massoum,

Faculty of Electrical Engineering, Djillali Liabe University,

Sidi Bel Abbès, Algeria.

Email: ahmassoum@yahoo.fr
}

\begin{abstract}
By using the direct torque control (DTC), robust response in ac drives can be produced. Ripples of currents, torque and flux are oberved in steady state. space vector modulation (SVM) applied in DTC and used for a sensorless induction motor (IM) with fuzzy sliding mode speed controller (FSMSC) is studied in this paper. This control can minimize the torque, flux, current and speed pulsations in steady state. To estimate the rotor speed and stator flux the model reference adaptive system (MRAS) is used that is designed from identified voltages and currents. The FSMSC is used to enhance the efficiency and the robustness of the presented system. The DTC transient advantage are maintained, while better quality steady-state performance is produced in sensorless implementation for a wide speed range. The drive system performances have been checked by using Matlab Simultaion, and successful results have been obtained. It is deduced that the proposed control system produces better results than the classical DTC.
\end{abstract}

This is an open access article under the $\underline{C C B Y-S A}$ license.

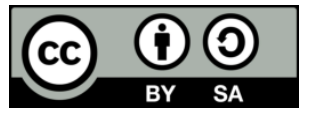

\section{INTRODUCTION}

The asynchronous motor in the industrial applications has many advantages such as the robustness, its low cost, its performances and the maintenance simplicity. Power electronics and numerical control ensure today to consider the control of the variable speed. Applying the various technologies, the scientific developed different control approaches to overcome, in electrical machines, the flux and the torque. So, the situation has however changed dramatically with the advent of DTC [1] and speed sensorless control [2]. Since 1985, the DTC was completly used for induction motor. The torque and the flux have to be correctly estimated. A correct estimation of the torque and the flux enable DTC to develop fast torque and flux control [3]. After all, torque, flux, and current pulsations occur in steady state operation. They are reproduced in torque, flux and speed estimation.

To overcome some of the desavantages of DTC, many techniques have been proposed [4, 5]. Among these solutions proposed: DTC with Space Vector Modulation (DTC-SVM) [6, 7]; DTC based on artificial intelligence techniques [8,9]. The need for sensorless speed control of induction machines has become requiered. The mechanical speed sensor needs maintenance in many application which make the sensor intallation difficult. For these advantages, most industry admit that the succeding production of commercial drives will use any type of sensorless control. For speed-sensorless DTC-IM drives many system have been proposed, which use stator currents and voltages measurements to estimate the mechanical speed. 
When this mechanical sensor is removed from any studied system, it's demontrated that, in hostile environnement, the maintenance is less troublesome. The MRAS-based speed estimators seem to be the best of the different improvements that have been suggested. The principle of DTC, desides an estimate the mechanical speed estimation, the model reference adaptive system allow the estimate of the stator flux that is used in DTC for the inducrion motor. For their simplicity and their proven stability, the MRAS-based estimators are preferred [10]. The speed classical controller used in DTC-SVM-IM presents performance when changing parameter and imperfect rejection once the load torque and perturbations are applied which needs the application of robust control. To give good better performances, a combination has been made between the sliding mode controller and the Fuzzy Logic to configurate the Fuzzy Sliding Mode Controller (FSMC) for sensorless speed drive.

The DTC principle of the IM is described in the second section. The third section is devoted to the presentation of the DTC-SVM. Section four is dedicated to the application of MRAS to the DTC-SVMIM. Sensorless motor based on FSMSC for DTC-SVM is analyzed in fifth section. In the sixth section the simulation results of the studied control topology are presented. At the end conclusions and perspectives will be discussed in the seventh section.

\section{PRINCIPLE OF DTC}

In Figure 1, the classical DTC block diagram is presented. Two different hystereris regulators are used to control the magnitudes of the stator flux and torque. The selection of the right voltage vector according to the switching process is given in Table 1 .

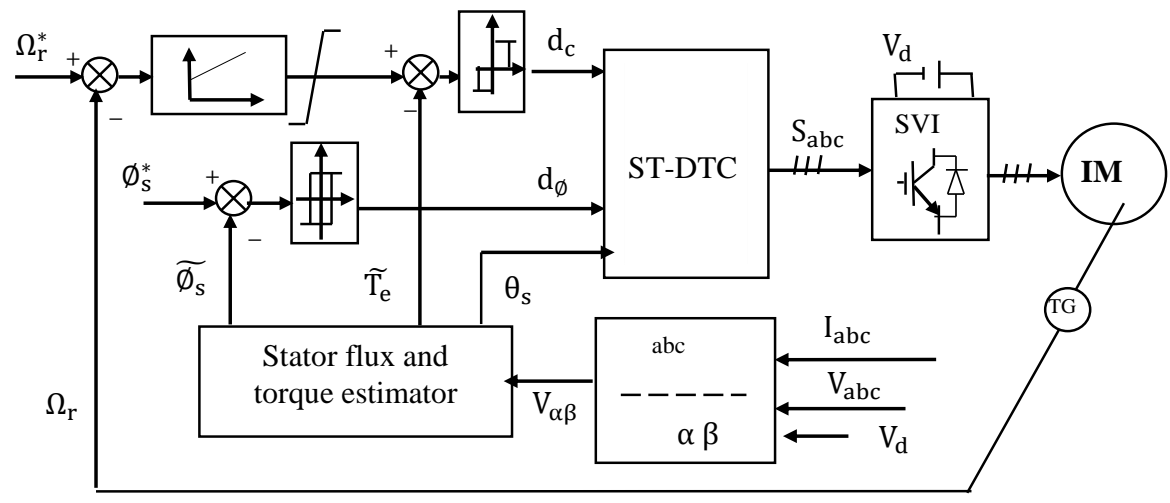

Figure 1. Classical speed regulator using ST-DTC

Table 1. Basing switching

\begin{tabular}{cccccccc}
\hline$\emptyset_{\mathrm{s}}$ & $\mathrm{C}_{\mathrm{e}}$ & $\mathrm{z}_{1}$ & $\mathrm{z}_{2}$ & $\mathrm{z}_{3}$ & $\mathrm{z}_{4}$ & $\mathrm{z}_{5}$ & $\mathrm{z}_{6}$ \\
\hline \multirow{3}{*}{$\mathrm{d}_{\varnothing}=\mathrm{o}$} & $\mathrm{d}_{\mathrm{c}}=1$ & $\mathrm{~V}_{3}$ & $\mathrm{~V}_{4}$ & $\mathrm{~V}_{5}$ & $\mathrm{~V}_{6}$ & $\mathrm{~V}_{1}$ & $\mathrm{~V}_{2}$ \\
& $\mathrm{~d}_{\mathrm{c}}=\mathrm{o}$ & $\mathrm{V}_{0}$ & $\mathrm{~V}_{7}$ & $\mathrm{~V}_{0}$ & $\mathrm{~V}_{7}$ & $\mathrm{~V}_{0}$ & $\mathrm{~V}_{7}$ \\
& $\mathrm{~d}_{\mathrm{c}}=-1$ & $\mathrm{~V}_{5}$ & $\mathrm{~V}_{6}$ & $\mathrm{~V}_{1}$ & $\mathrm{~V}_{2}$ & $\mathrm{~V}_{3}$ & $\mathrm{~V}_{4}$ \\
& $\mathrm{~d}_{\mathrm{c}}=1$ & $\mathrm{~V}_{2}$ & $\mathrm{~V}_{3}$ & $\mathrm{~V}_{4}$ & $\mathrm{~V}_{5}$ & $\mathrm{~V}_{6}$ & $\mathrm{~V}_{1}$ \\
$\mathrm{~d}_{\varnothing}=1$ & $\mathrm{~d}_{\mathrm{c}}=\mathrm{o}$ & $\mathrm{V}_{7}$ & $\mathrm{~V}_{0}$ & $\mathrm{~V}_{7}$ & $\mathrm{~V}_{0}$ & $\mathrm{~V}_{7}$ & $\mathrm{~V}_{0}$ \\
& $\mathrm{~d}_{\mathrm{c}}=-1$ & $\mathrm{~V}_{6}$ & $\mathrm{~V}_{1}$ & $\mathrm{~V}_{2}$ & $\mathrm{~V}_{3}$ & $\mathrm{~V}_{4}$ & $\mathrm{~V}_{5}$ \\
\hline
\end{tabular}

The stator flux and output torque can be estimated by using only the current and voltage measurements. The control of the closing and the opening inverter switches is ensured by the computed values of stator flux and torque. The state's changes of the switches are related to the evolution of the electromagnetic state of the motor. The outer speed control loop is assured by a PI controller to accomplish quick response and acceptable overshoot and static error [11,12].

\subsection{Control of stator flux}

The (1) using voltage model, permits to estimate stator flux:

$$
\bar{\emptyset}_{s}=\int_{o}^{t}\left(\bar{V}_{s}-R_{s} \bar{I}_{s}\right) d t
$$


when the resistance of the stator is abondoned in high speed operating status. The amplitude of voltage vector can be used to determine the instantaneous flux speed. DC link voltage $V_{d c}$, inverter switching states $S_{a}, S_{b}$, and $S_{c}$ and the motor line currents $I_{a b c}$ are used to compute $\bar{V}_{s}$ and $\bar{I}_{s}$. The following equation gives the relationship between the rotor flux and stator flux:

$$
\begin{aligned}
& \bar{\emptyset}_{s}(k+1) \approx \bar{\emptyset}_{s}(k)+\bar{V}_{s} T_{e} \text { or } \Delta \bar{\emptyset}_{s}(k)=\bar{V}_{s} T_{e} \\
& \bar{\emptyset}_{r}=\frac{L_{m} / L_{s}}{1+s \delta T_{r}} \bar{\emptyset}_{s}
\end{aligned}
$$

The stator flux angle is calculated by:

$$
\theta_{s}=\arctan \left(\emptyset_{q s} / \emptyset_{d s}\right)
$$

\subsection{Control of electromagnetic torque}

The electromagnetic torque is related to the stator and rotor flux vector by the following expression:

$$
T_{e}=\frac{3}{2} \frac{p M}{L_{r} L_{s}}\left(\emptyset_{d s} I_{q s}-\emptyset_{q s} I_{d s}\right)
$$

\section{SVM-DTC PRINCIPLE}

It can be shown that ST-DTC drive has a good dynamic response but large torque ripple and the frequency of switching for the VSI. This problems may be mastered by the SVM based DTC method which is presented in this section. In this strategy, the $\mathrm{d}-\mathrm{q}$ coordinates of the reference voltage vector are derived directly from the state of the outputs of the torque and flux regulators. The expression of the voltage coordinates is:

$$
\left\{\begin{array}{c}
U_{d s}^{*}=K_{d} E\left(2 c_{f}-1\right) \\
U_{q s}^{*}=K_{q} E\left(2 c_{T}-1\right)-\omega_{s} \emptyset_{s}^{*}
\end{array}\right.
$$

$\mathrm{c}_{\mathrm{f}}, \mathrm{c}_{\mathrm{T}} \in[0,1]$ are respectively the on-off controller binary output of the magnitude stator flux and the torque; $\mathrm{K}_{\mathrm{d}}, \mathrm{K}_{\mathrm{q}}$ are coefficients that belong to the interval [0,1]; $\mathrm{E}$ is the dc link voltage. Expression (5) can be given by Figure 2 .

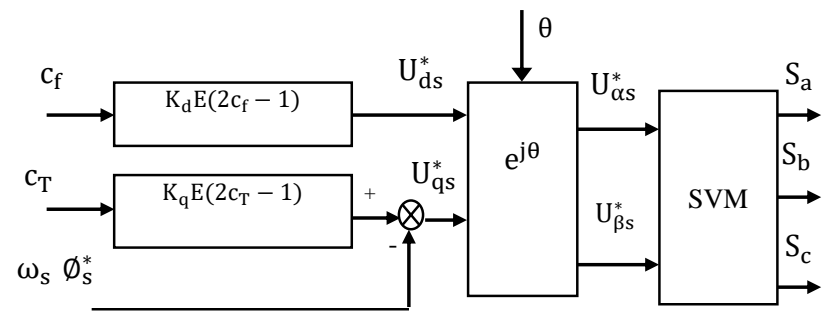

Figure 2. Description of the voltage vector generation

The space vector of the phase voltages, in the stationary framework, can be written as:

$$
\bar{V}_{s}=\frac{2}{3} E\left[S_{a}+S_{b} e^{j \frac{2 \pi}{3}}+S_{c} e^{j \frac{4 \pi}{3}}\right]
$$

SVM is an algorithm for the control of pulse width modulation (PWM) destined to synthesize a required voltage space vector at the inverter output terminals. The operation of SVM is to decompose $\bar{V}_{S}$ into the sum of the two adjacent active voltage space vectors of the inverter and of zero space vectors and by applying them the modulation period $T_{e c}$ equal to the weights of that sum. If $\bar{V}_{s}$ is as shown in Figure 3, it may be devided into: 


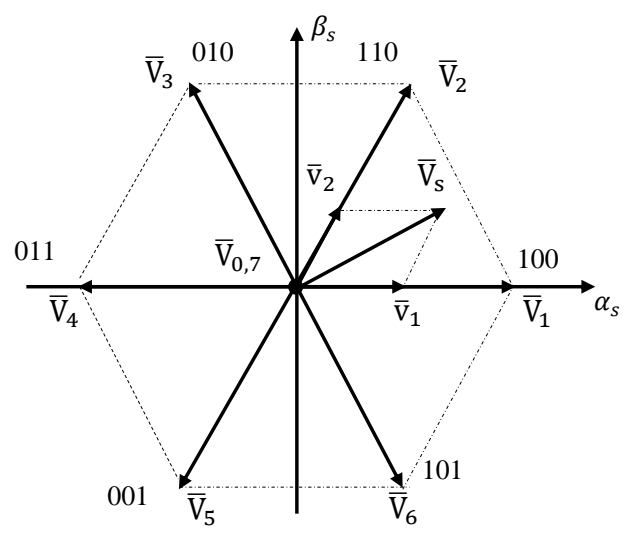

Figure 3. $\overline{\mathrm{V}}_{\mathrm{s}}$ Decomposition

$$
\begin{aligned}
& \bar{V}_{s}=a_{1} \bar{V}_{1}+a_{2} \bar{V}_{2}+a_{o} \bar{V}_{o}+a_{7} \bar{V}_{7} \\
& a_{1}=\frac{\bar{v}_{1}}{\bar{V}_{1}}, a_{2}=\frac{\bar{v}_{2}}{\bar{V}_{2}}, a_{o}+a_{7}=1-a_{1}-a_{2}
\end{aligned}
$$

The equal amplitude of $(2 / 3) \mathrm{E}$ and a phase of $(\mathrm{k}-1) \pi / 3$ accomplish the active space vectors $(\mathrm{k}=1,2, \ldots, 6)$. The left two space vectors $(\mathrm{k}=0,7)$ are zero vectors [13-17], and the inverter voltage space vectors $\overline{\mathrm{V}}_{\mathrm{k}}(\mathrm{k}=1,2)$ are implemented for: $\mathrm{T}_{\mathrm{k}}=\mathrm{a}_{\mathrm{k}} \mathrm{T}_{\mathrm{ec}}, \mathrm{k}=1,2,0,7$; by controlling switches, see Figure 4:

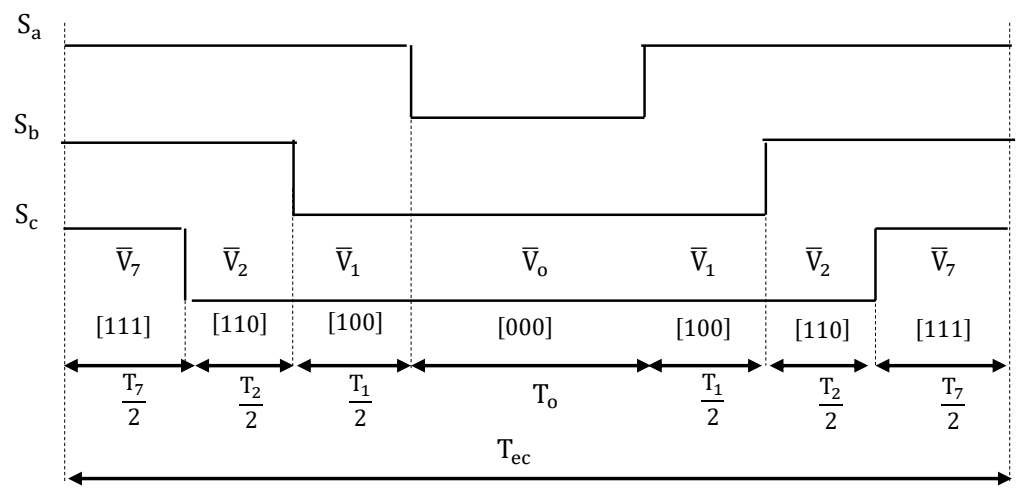

Figure 4. SVM switch commands

\section{MRAS TO ESTIMATE ROTOR SPEED}

To ovoid maintenance, the speed sensor can be removed preserving correct reponse, which permits the utility of the widely use of sensorless drives. The estimation of the necessary control variables can be assured by tracking the stator current and stator voltages. In this part the model reference adaptive system (MRAS) is used [18, 19]. The operation block of the MRAS is made as shown Figure 5. The design of the MRAS, and in addition to an Adaptative mechanism, is contructed of two models: reference model and adjustable models. Independently of the speed, the reference model presents voltage model. The second model that is the adjustable model is the current model that uses rotor speed as an input to adjust the output parameter. The error given by the outputs of the two mentioned models are used by the adaptation mechanism (PI controller) to estimate the rotor speed which is fedback to the adjustable model to update the estimated value until the best tracking is accomplished. The accuracy of the estimated parameter can be increased, till the MRAS is considered as a close-loop systeme. Relative to the expressions that define the MRAS, the different models include integrators which create error in the estimation process caused by the unspecified original situation and estimate drift due to in the measured currents. To bypass the trouble, low-pass filters are used [20-23]. 


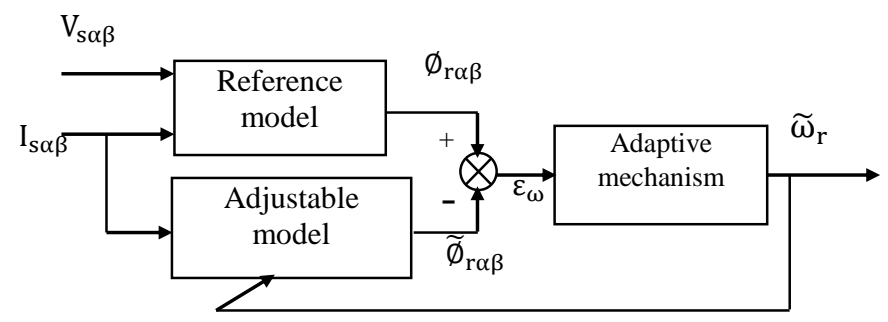

Figure 5. Classical MRAS structure for speed estimation

\subsection{Equations of reference model}

The reference model gives the components of the reference rotor flux that is given by:

$$
\left[\emptyset_{r \alpha \beta}\right]=\frac{L_{r}}{L_{m}}\left(\int\left(\left[V_{s \alpha \beta}\right]-R_{S}\left[I_{s \alpha \beta}\right]\right) d t-\sigma L_{s}\left[I_{s \alpha \beta}\right]\right)
$$

\subsection{Equations adaptive model}

The adaptive model provide the components of rotor flux, which is given by [24-26]:

$$
\left[\widetilde{\emptyset}_{r \alpha \beta}\right]=\int\left(\left(-\frac{1}{T_{r}}+\omega_{r}\right)\left[\widetilde{\emptyset}_{r \alpha \beta}\right]+\frac{L_{m}}{T_{r}}\left[I_{s \alpha \beta}\right]\right) d t
$$

\subsection{Error generated by the two models}

In order to reduce the error generated between the estimated value and the reference the adaptative mechanism track the value of the estimated speed to be feedback to the adaptative model. This can be accomplished by computing speed adjusting signal $\varepsilon_{\omega}$ that is reduced by a PI controller which causes the observed speed. The speed adjusting signal and the estimated speed are defined by the (10):

$$
\begin{aligned}
& \varepsilon_{\omega}=\left(\emptyset_{r \beta} \widetilde{\emptyset}_{r \alpha}-\emptyset_{r \alpha} \widetilde{\emptyset}_{r \beta}\right) \\
& \widetilde{\omega}_{r}=k_{p} \varepsilon_{\omega}+k_{i} \int \varepsilon_{\omega} d t
\end{aligned}
$$

\section{CONTROL USING FUZZY SLIDING MODE}

FSMC is utilized to design controller for systems whose parameters varyand which cannot be precisely modelled and [27, 28]. Considering the mechanical equation, the sliding mode speed controller for the induction motor DTC-SVM drive may be developed as:

$$
\frac{J}{p} \dot{\omega}_{r}+\frac{K_{f}}{p} \omega_{r}+T_{r}=T_{e}
$$

where $\omega_{r}$ is the speed of the rotor $(\mathrm{rad} / \mathrm{s})$ and defined as:

$$
\dot{\omega}_{r}=\frac{p}{J} T_{e}-\frac{K_{f}}{J} \omega_{r}-\frac{p}{J} T_{r}
$$

$\Delta a$ and $\Delta b$ introduced by system parameters $J$ and $K_{f},(12)$ can be rewritten as:

$$
\dot{\omega}_{r}=(a+\Delta a) \omega_{r}+(b+\Delta b) T_{e}+c T_{r}
$$

where $a=-\frac{K_{f}}{J}, b=\frac{p}{J},=-\frac{p}{J}$.

The error of the speed is defined as:

$$
e(t)=\omega_{r}(t)-\omega_{r}^{*}(t)
$$

Combining (13) with (14) and derive (14) gives:

$$
\dot{e}(t)=a e(t)+b\left\{\bar{T}_{e}+d(t)\right\}
$$


$d(t)$ is the lumped uncertainty given by:

$$
d(t)=\frac{\Delta a}{b} \omega_{r}(t)+\frac{\Delta b}{b} T_{e}+\frac{c}{b} T_{r}
$$

and:

$$
\bar{T}_{e}(t)=T_{e}(t)+\frac{a}{b} \omega^{*}
$$

Switching surface $s(\mathrm{t})$ from $a$ and $b$ is defined as:

$$
s(t)=e(t)-\int_{0}^{t}(a+b k) e(\tau) d \tau
$$

So that the sliding surface $s(t)=\dot{s}(t)=0$, then the error may be defined by:

$$
\dot{e}(t)=(a+b k) e(t)
$$

where $k$ is a linear negative gain [29]. The law that define the control of the speed can be given by:

$$
\overline{T_{e}}=k e(t)-\beta \operatorname{sign}(s(t))
$$

where $\beta$ is recognized as control gain. This gain is used to adapt the sliding mode condition. The sign function used in this sliding mode control is given by:

$$
\operatorname{sign}(s)=\left\{\begin{array}{rlc}
1 & \text { if } & s>0 \\
0 & \text { if } & s=0 \\
-1 & \text { if } & s<0
\end{array}\right.
$$

By substituting (17) into (20), the output of the speed controller based on sliding mode technique is represented by the electromagnetic torque $T_{e}^{*}$. The principle of the control law (SMC) for $T_{e}^{*}$ can be divided into two parts: equivalent control $U_{e q}$ which describe the action of the control used whenever the system is on the sliding mode and switching control $U_{S}$ which guarantees the existence requierement of the sliding mode. Neglecting $B$, the equations for $U_{e q}$ and $U_{s}$ become:

$$
\left\{\begin{array}{l}
U_{e q}=k e(t) \\
U_{s}=-\beta \operatorname{sign}(s(t))
\end{array}\right.
$$

An approach of sliding mode controller design is to look at Lyapunov function [6]:

$$
V(t)=\frac{1}{2} s^{2}(t)
$$

The Lyapunov theory is based on the fact that if the expression of $\dot{V}(t)$ is negative, this will guarantee attractive condition of the sliding mode. When the sliding surface $S(t)$ is attained, it will stay moving on it till it reaches the origin asymptotically [30]. Hold the differential of (23) and replacing from the differentiel of (18):

$$
\dot{V}(t)=s(t) \dot{s}(t)=s(t)\{\dot{e}(t)-(a+b k) e(t)\} \leq 0
$$

Substitute from (15) into (24):

$$
s(t) \dot{s}=s(t)\left\{b \overline{C_{e}}(t)+b d(t)-b k e(t)\right\}
$$

Using (20) gives:

$$
s(t) \dot{s}=s(t)\{-\beta \operatorname{sign}(s(t))-d(t)\} \leq 0
$$


To guarantee that (26) will stay negative, the value of the hitting control gain $\beta$ has to be at the upper bound of the lumped ambiguity $d(t)$, i.e.

$$
\beta \geq|d(t)|
$$

On the other hand, it is difficult practically to estimate the bound of uncertainties. Consequently, and in order to overcome the effect of any external perturbation, the hitting control gain $\beta$ has to be selected big sufficiently $[8,11]$. Hence, the equation (20), that define the law to control speed, will ensure the entity of the switching surface $s(t)$ in (18) and when the function $e(t)$ of the error arrives at the sliding surface, the system will be supervised by equation (19) that is every time invariable [26]. Farthermore, the control system will be indifferent to $\Delta a, \Delta b$ and the perturbation $C_{r}$. An application of the sign function in the sliding mode control (20) will generate fluctuations due to the discontinuous control action that generate trouble when the system approches thesurface of sliding [27]. To solve this phenomenon, Fuzzy logic combined with sliding mode is used. The fuzzy inference system replaces the saturation function to eliminate the fluctuations. The Fuzzy sliding mode controller is a SISO (single input single output) controller based on fuzzy logic which is deigned and based on 'IF....THEN' rules. The inference method is described by using the max-min method. The center of the area defuzzifier is used to obtain the crisp output. The fuzzy logic controller uses the If-Then rules that may be defined as [31-33]:

If $\mathrm{s}$ is $\mathrm{BN}$ then $U_{s}$ is Bigger

If $\mathrm{s}$ is $\mathrm{MN}$ then $U_{s}$ is $\mathrm{Big}$

If $\mathrm{s}$ is $\mathrm{JZ}$ then $U_{s}$ is Medium

If $\mathrm{s}$ is MP then $U_{s}$ is Small

If $\mathrm{s}$ is $\mathrm{BP}$ then $U_{s}$ is Smaller

Where BN: Big Negative; MN: Medium Negative; JZ: Just Zero; MP: Medium Positive; BP: Big Positive. The trial error is used to obtain the membership functions for the input and output of the controller based on fuzzy logic to guarantee best efficiency, see Figure 6 :
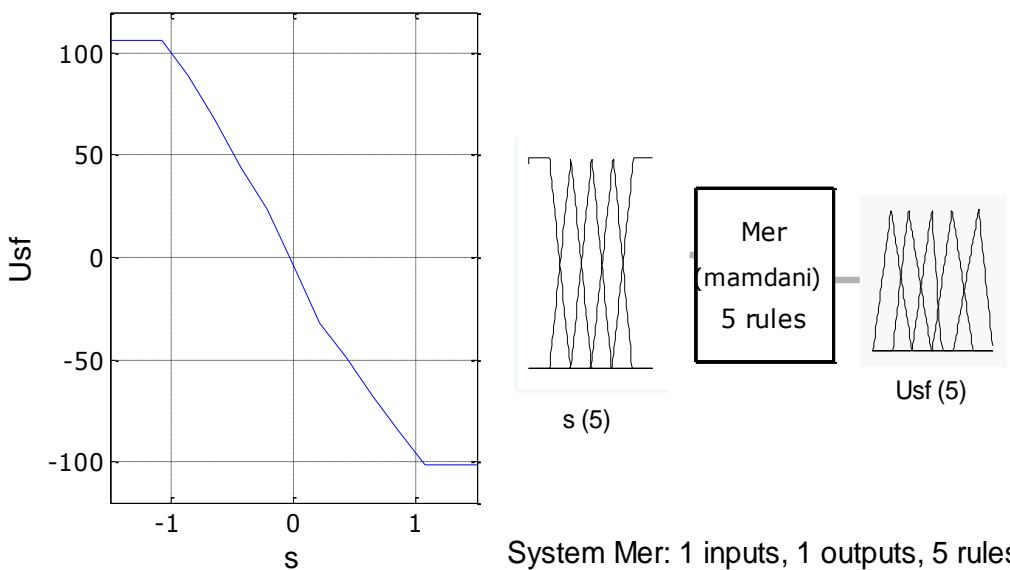

Figure 6. Fuzzy sliding mode switching and fuzzy logic membership functions

\section{RESULTS AND DISCUSSION}

Matlab/Simulink and Fuzzy logic Toolbox have been used to analyse the efficiency of the controller based on fuzzy sliding mode for a sensorless speed control and direct torque control with SVM technique. The switching frequency is obtained from the use of the hysteresis bands of the torque and flux of $0.2 \mathrm{Nm}$ and $0.01 \mathrm{~Wb}$ respectively. The specifications The studied induction motor are: $1.5 \mathrm{kw}, 380 / 220 \mathrm{~V}, 4 \mathrm{poles}, 50 \mathrm{~Hz}$, $R_{s}=4.85 \Omega, \quad R_{r}=3.805 \Omega, \quad L_{s}=0.274 \mathrm{H}, \quad L_{r}=0.274 \mathrm{H}, \quad$ and $\quad L_{m}=0.258 \mathrm{H}, \quad \mathrm{J}=0.031 \mathrm{~kg} \cdot \mathrm{m}^{2}$, $f_{r}=0.000114 \mathrm{Nm} . \mathrm{s}^{-1}$. Figure 7 shows classical DTC where the references are the torque reverse from $+10 \mathrm{Nm}$ to $-10 \mathrm{Nm}$ and the stator flux $1 \mathrm{~Wb}$.

It is clear that the system follows these references. The torque and the stator flux are decoupled. The transient regimes are very fast as shown in Figure 8. It can be seen, later on transitory instance, the estimated speed of the rotor follow the desired speed despite of system ambiguity $\mathrm{s}$ in the same way that real mechanical speed. The speed presents a fast response without overshoot and static error. The load disturbance is rejected rapidly. It can be noticed the decoupling between the stator flux and 
the electromagnetic torque, see Figure 9. To improve the effeciency and robustness of the system, we replace PI speed controller by a FSMC and the ST-DTC by SVM-DTC, we obtain the results in Figure 10.
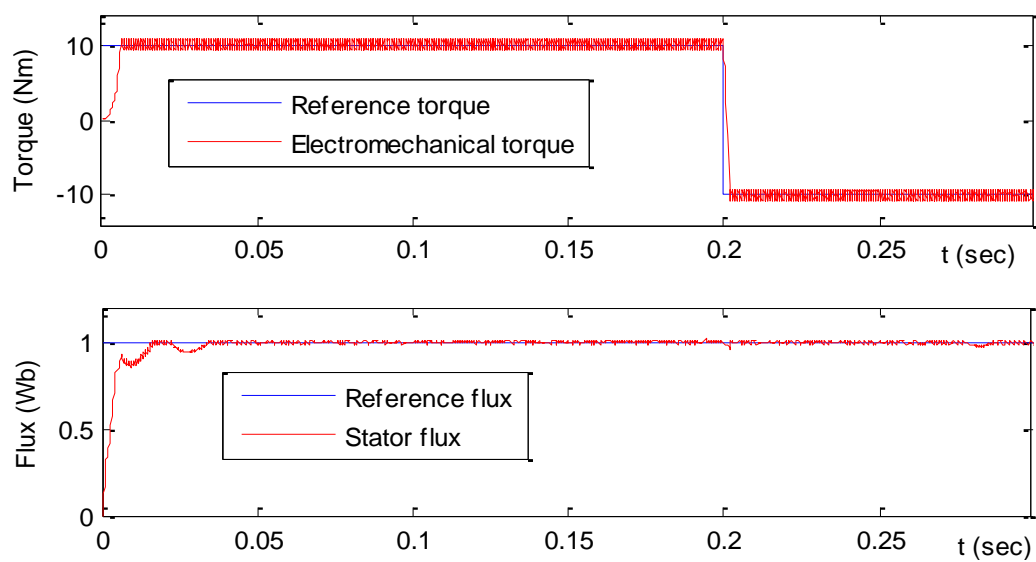

Figure 7. Classical responses ST-DTC

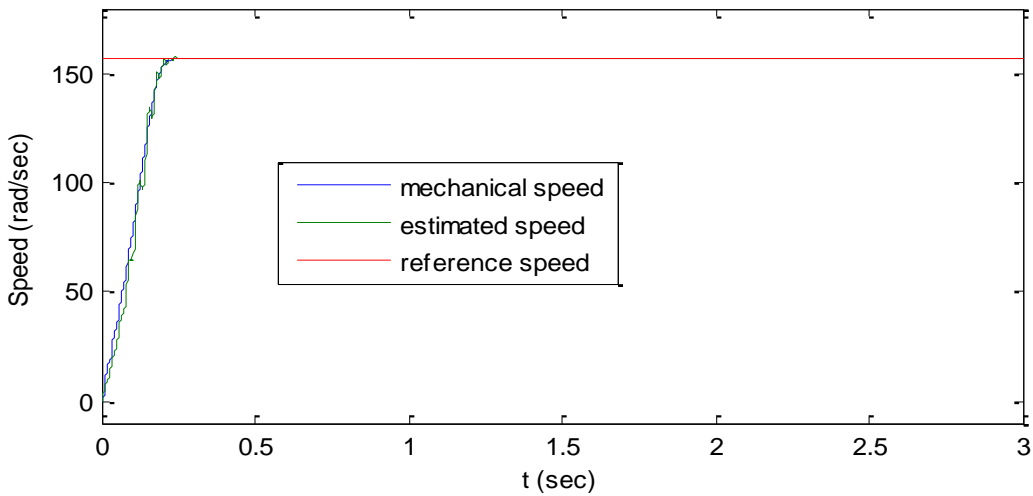

Figure 8. Speed responses
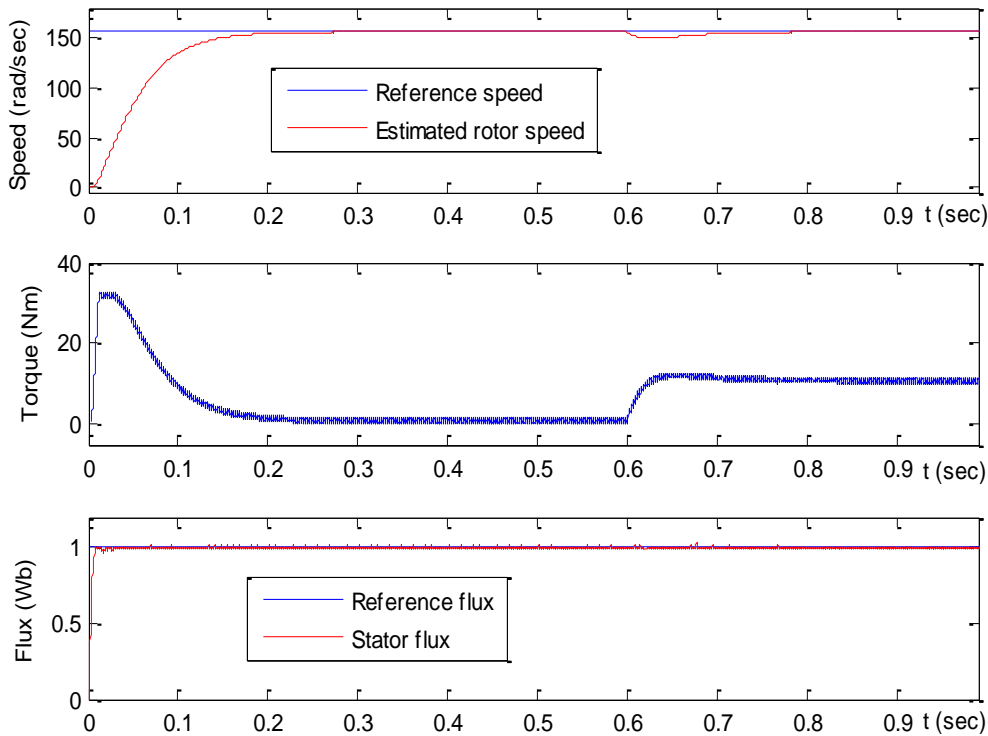

Figure 9. PI Speed controller for ST-DTC 

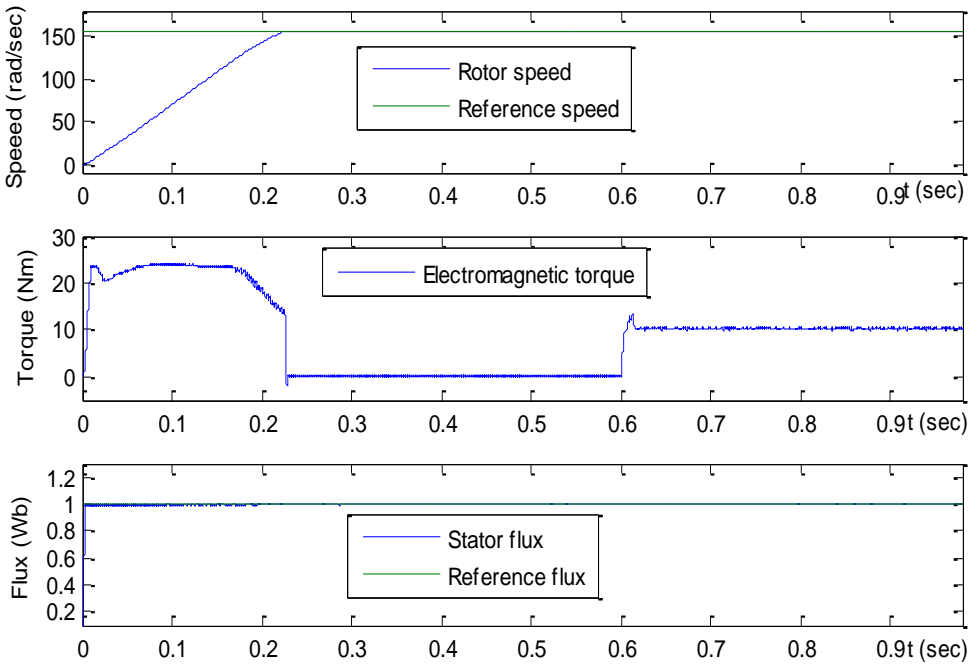

Figure 10. The FSM speed controller for SVM-DTC

The command input is step reference for speed and the system is loaded at $0.6 \mathrm{~s}$ with $10 \mathrm{Nm}$. It may be observed that the speed response present a good performances (quick response with no overshoot, zero steady state error and good following reference speed). Applied external perturbation on the speed response is eliminated. The decoupling properties are ensured and flux tracks the required flux accurately.

- Tests of robustness: For testing the robustness of the studied system control, changes on stator resistance and inertia have been accomplished.

- Variation in the stator resistance: The modification of stator resistance highly affects the effeciency of the DTC drive, see Figure 11.

Figure 11 shows the robustness of the fuzzy sliding mode controller applaying variation on the stator resistance and torque perturbation $\mathrm{C}_{\mathrm{r}}$. The system keeps its performances of decoupling. We notice a light increase in the speed response time.

- Inertia variation: An additional test is realized by assigning step change in speed control with inertia variation. Figure 12 shows the behavior of the drive when inertia is increased $100 \%$ of its nominal value.

Figure 12 shows that the reference speed is tracked precisely caused by the robustness of the fuzzy sliding mode controller. It can be noticed that the time speed response augments with inertia and all the other effenciencies are conserved.

- Reduction of ripples: A comparision has been made between PI-ST-DTC and FSMC-SVM-DTC, to show the effect of chattering: From examination of Figure 13, it can be deduced that ripples of the torque in steady state is progressively decreased FSMC-SVM-DTC.
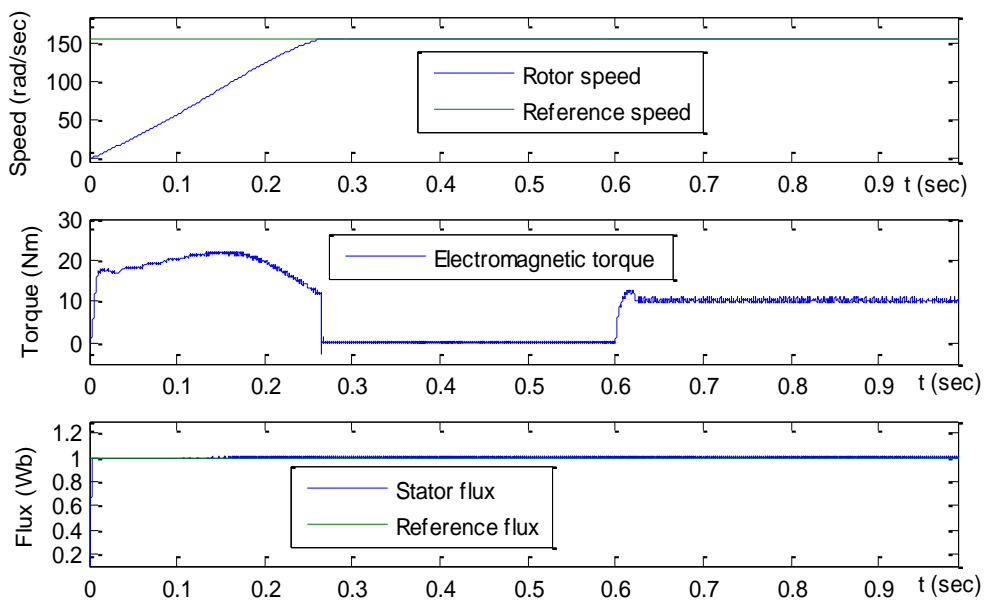

Figure 11. Speed fuzzy sliding mode controller with $R_{s}=1.5 R_{s n}$ 

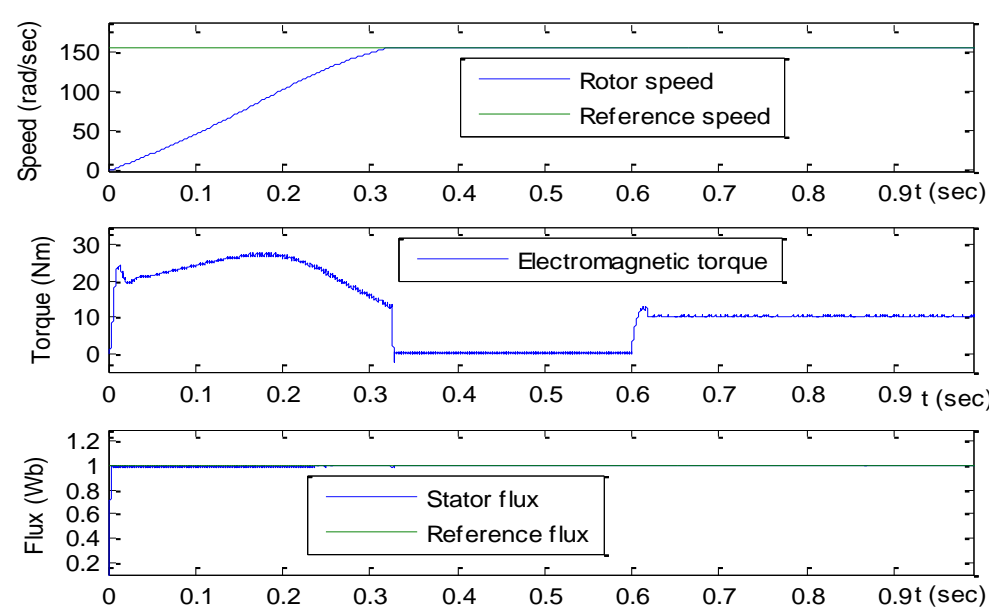

Figure 12. Responses with rotor inertia $J=1.5 J_{n}$
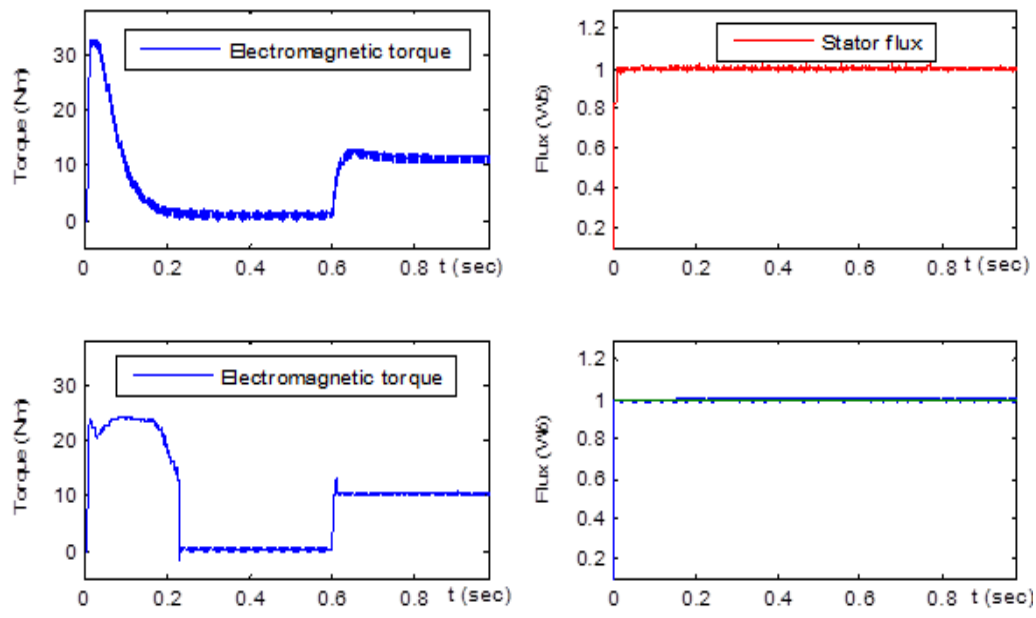

Figure 13. PI with ST-DTC and FSMC-SVM-DTC

\section{CONCLUSION}

A control strategy for induction motor without speed senor, developed on a DTC-SVM, has been described. From responses, it was proven that the proposed fuzzy sliding mode controller is robust to external changes and has filed adequate effeciencies in speed response (no overshoot, zero steady state error and good tracking reference speed). The test of robustness has proven that it is insensible to load changes.

With the application of the parameter variations and external load perturbation, the decoupling between the stator flux and the torque is preserved. The chattering has been decreased in torque and flux. The fuzzy sliding mode controller produces reduction in flux and in torque ripples. The fuzzy logic function of the FSMC is realized without taking into account the machine model. With reduced flux and torque chattering, it can be deduced that current harmonics and vibrations are decreased.

\section{REFERENCES}

[1] I. Takahashi and T. Noguchi, "A new quick response and high efficiency control strategy of an induction motor," in Proceedings of IEEE Transactions on Industry Applications, vol. IA-22, no. 5, pp. 820-827, 1986.

[2] A. Paladugu and H. B. Chowdhury, "Sensorless control of inverter-fed induction motor drives," Electric Power Systems Research, vol. 77, no. 5-6, pp. 619-629, 2007.

[3] Y. P. Obulesu and M. V. Kumar, "Design and simulation of direct torque control of Induction Motor drive using Matlab/Simulink," International Journal of Power and Energy Systems, vol. 27, pp. 103-112, 2007.

[4] J. L. Romeral, et al., "Novel direct torque control (DTC) scheme with fuzzy adaptive torque ripple reduction," IEEE Transaction on Industrial Electronics, vol. 50, no. 3, pp. 487-492, 2003. 
[5] I. G. Bird and H. Zelaya, "Fuzzy logic torque ripple reduction for DTC based AC dives," Electronics Letter, vol. 33, no. 17, pp. 1501-1502, 1997.

[6] M. J. M. Al-khishalib and A. I. Al-Shawi, "Space Vector Modulation Direct Torque Speed Control of Induction Motor," Procedia Computer Science, vol. 5, pp. 505-512, 2011.

[7] M. M. Rezaei and M. Mirsalim, "Improved Direct Torque Control for Induction Machine Drives Based on Fuzzy Sector Theory," Iranian Journal of Electrical \& Electronic Engineering, vol. 6, no. 2, pp. 110-118, 2010.

[8] X. Ding, et al., "The Fuzzy Direct Torque Control of Induction Motor based on Space Vector Modulation," Third International Conference on Natural Computation (ICNC 2007), vol. 4, pp. 260-264, 2007.

[9] R. Kumar, et al., "Artificial Neural Network based Direct torque Control of Induction Motor Drives," IETECH Journal of Electrical Analysis, vol. 2, pp. 159-165, 2008.

[10] R. Gunabalan and V. Subbiah, "Speed Sensorless Vector Control of Induction Motor Drive with PI and Fuzzy Controller," International Journal of Power Electronics and Drive System (IJPEDS), vol. 5, no. 3, pp. 315-325, 2015.

[11] U. Mahanta, et al., "Dynamic simulation of ST-DTC with three-level inverter for three-phase induction motor," International Conference on Power and Embedded Drive Control (ICPED 2017), pp. 526-532, 2017.

[12] H. Kantari, "K Direct Torque Control of Induction Motor Using Space Vector Modulation (SVM-DTC)," International Journal of Modern Engineering Research (IJMER), vol. 2, no. 5, pp. 3747-3768, 2012.

[13] H. Hiba, et al., "DTC-SVM control for three phase induction motors," International Conference on Electrical Engineering and Software Applications (ICEESA 2013), pp. 1-7, 2013.

[14] M. T. Lazim, et al., "Space Vector Modulation Direct Torque Speed Control of Induction Motor," Procedia Computer Science, vol. 5, pp. 505-512, 2011.

[15] H. Kantari, "Direct Torque Control of Induction Motor Based on Space Vector Modulation Using a Fuzzy Logic Speed Controller," Jordan Journal of Mechanical and Industrial Engineering, vol. 8, pp. 169-176, 2014.

[16] J. Listwan and K. Pieńkowski, "DTC-ST and DTC-SVM Control of Five-Phase Induction Motor: with MRAS estimator," Przeglad Elektrotechniczny, vol. 92, pp. 252-256, 2016.

[17] S. K. Barika and K. K. Jaladib, "Five-Phase Induction Motor DTC-SVM scheme with PI Controller; and ANN controller," Procedia Technology, vol. 25, pp. 816-823, 2016.

[18] S. M. Mousavi and A. Dashti, "Application of Speed Estimation Techniques for Induction Motor Drives in Electric Traction Industries and vehicles," International Journal of Automotive Engineering, vol. 4, pp. 857-868, 2014.

[19] A. S. Altay, et al., "Sensorless speed control of a vector controlled three-phase induction motor drive by using MRAS," Journal of Vibroengineering, vol. 16, no. 3, pp. 1258-1267, 2014.

[20] Y. A. Zorgani, et al., "MRAS state estimator for speed sensorless ISFOC induction motor drives with Luenberger load torque estimation," ISA Transactions, vol. 61, pp. 308-317, 2016.

[21] S. M. M. Gazafroodi and A. Dashti, "A Novel MRAS Based Estimator for Speed-Sensorless Induction Motor Drive," Iranian Journal of Electrical \& Electronic Engineering, vol. 10, pp. 304-313, 2014.

[22] C. Djamila, et al., "Robust MRAS-Based Algorithm for Rotor Resistance and Rotor Speed Estimation of Indirect Vector Controlled Induction Motor Drive," International Journal on Energy Conversion (IRECON), vol. 1, no. 2, pp. 133-140, 2013.

[23] M. Dybkowski and T. O. Kowalska, "Speed Sensorless Induction Motor Drive System with MRAS type Speed and Flux Estimator and Additional Parameter Identification," IFAC Proceedings Volumes, vol. 46, pp. 33-38, 2013.

[24] M. Zair and A. Hazzab, "MRAS Speed Sensorless Vector Control of Induction Motor Drives using Predictive Adaptation Mechanism," International Journal of Power Electronics and Drive System (IJPEDS), vol. 9, no. 4, pp. 1523-1533, 2018.

[25] V. Verma, "Current sensorless vector controlled induction motor drive," International Journal of Robotics and Automation (IJRA), vol. 8, pp. 52-67, 2019.

[26] S. Loui, et al., "Exponential Reaching Law and Sensorless DTC IM Control with Neural Network Online Parameters Estimation based on MRAS," International Journal of Robotics and Automation (IJRA), vol. 7, pp. 77-86, 2018.

[27] H. Alli and O. Yakut, "Fuzzy sliding-mode control of structures," Engineering Structures, vol. 27, pp. 277-284, 2005.

[28] Q. P. Ha, et al., "Fuzzy sliding-mode controllers with applications," IEEE Transactions on Industriel Electronics, vol. 48, pp. 38-46, 2001.

[29] M. Derri, et al., "Fuzzy Sliding Mode Control for Photovoltaic System," International Journal of Power Electronics and Drive System (IJPEDS), vol. 7, no. 3, pp. 964-973, 2016.

[30] A. Meroufel, et al., "A Fuzzy Sliding Mode Controller for a Vector Controlled Induction Motor," IEEE International Symposium on Industrial Electronics (ISIE 2008), pp. 1873-1878, 2008.

[31] R. G. Raj and B. Palpandi, "Development of Fuzzy Logic-Based Speed Control of Novel Multilevel Inverter-Fed Induction Motor Drive," Applied Mathematics \& Information Sciences An International Journal, vol. 12, pp. 745-752, 2018.

[32] Z. Mekrini and B, Seddik, "Fuzzy Logic Application for Intelligent Control of an Asynchronous Machine," Indonesian Journal of Electrical Engineering and Computer Science (IJEECS), vol. 7, no. 1, pp. 61-70, 2017.

[33] A. S. Handayani, et al., "Analysis on swarm robot coordination using fuzzy logic," Indonesian Journal of Electrical Engineering and Computer Science (IJEECS), vol. 13, no. 1, pp. 48-57, 2019. 